\title{
DE QUE FORMA A DISCIPLINA "LIBRAS" PODE CONTRIBUIR COM A FORMAÇÃO DE PROFESSORES PARA A EDUCAÇÃO INCLUSIVA?
}

\author{
HOW CAN THE DISCIPLINE "LIBRAS" CONTRIBUTE WITH TEACHER \\ TRAINING FOR THE INCLUSIVE EDUCATION? \\ ¿CÓMO LA ASIGNATURA “LIBRAS” PUEDE CONTRIBUIR CON LA \\ FORMACIÓN DEL PROFESORADO PARA LA EDUCACIÓN INCLUSIVA?
}

André Nogueira Xavier*

\section{Resumo}

O objetivo deste artigo é discutir de que maneira a disciplina "Libras" (Língua Brasileira de Sinais), obrigatória em cursos de licenciatura, pode contribuir ainda mais com a formação de professores no âmbito da educação básica inclusiva. Tendo em vista a falta de diretrizes nacionais para a constituição de uma ementa básica para essa disciplina, sugere-se a inclusão de tópicos, inferíveis da legislação que determina a sua obrigatoriedade nesses cursos, em seus conteúdos. Esses tópicos abrangem singularidades linguístico-culturais dos alunos surdos, questões históricas e filosóficas, bem como a atuação de tradutores-intérpretes de libras/português.

Palavras-chave: Libras. Licenciatura. Educação inclusiva.

\section{Introdução}

Embora a língua brasileira de sinais, libras, venha sendo, na prática, o meio de comunicação e expressão das pessoas surdas brasileiras, há bastante tempo o seu reconhecimento oficial por meio da Lei 10.436 de 24 de abril de 2002 é, indubitavelmente, uma das mais importantes conquistas do movimento político surdo nacional. Graças a essa lei e ao Decreto 5.626 de 22 de dezembro de 2005, que a regulamenta, deu-se início a uma série de políticas públicas que visam não apenas garantir os direitos linguísticos dos surdos brasileiros, mas também difundir sua língua. Entre essas políticas, destaca-se a inclusão da libras como componente curricular nos cursos de licenciatura. No âmbito da educação inclusiva, essa disciplina objetiva contribuir com a formação de educadores cientes das singularidades linguístico-

\footnotetext{
* Doutor em Linguística pelo Instituto de Estudos da Linguagem da Universidade Estadual de Campinas, UNICAMP. Professor do Curso de Licenciatura em Letras Libras da Universidade Federal do Paraná. E-mail: andrexavier@ufpr.br.
} 
culturais dos alunos surdos e assim garantir-lhes o direito à diferença e a condições equânimes de participação nos processos de ensino e aprendizagem da educação regular.

Diante da falta de diretrizes nacionais para a constituição da ementa da disciplina "Libras", este artigo objetiva discutir de que forma essa disciplina pode contribuir com a formação de futuros professores, ao familiarizá-los com alguns tópicos inferíveis da legislação, que estabelece sua inclusão obrigatória no currículo de cursos de licenciatura. Precisamente, propõe-se que, além da aprendizagem da língua propriamente, ainda que em nível elementar, discutam-se nessa disciplina desde questões históricas, filosóficas e linguístico-culturais, até as que envolvem a atuação de profissionais, uma vez que isso pode contribuir com práticas pedagógicas que salvaguardem a diferença dos alunos surdos. Antes de discutir cada um desses tópicos, no entanto, será apresentado um breve panorama dos eventos que antecedem e justificam a inclusão da disciplina "Libras".

\section{Dos primórdios do movimento político surdo à implantação da disciplina "Libras" nas licenciaturas}

Segundo Berenz (2003), a cidade do Rio de Janeiro pode ser considerada a capital do mundo surdo brasileiro, por ter sediado alguns dos principais eventos da história da comunidade surda nacional. Entre esses eventos citados por Berenz, estão a fundação, em 1857, da primeira escola de surdos do país, o atual Instituto Nacional de Educação de Surdos (INES); a criação da mais importante entidade representativa da comunidade surda brasileira, a Federação Nacional de Educação e Integração dos Surdos (FENEIS), em 1987, e a oferta, também no final da década de 1980, do primeiro curso de língua brasileira de sinais, libras, em uma universidade pública, a Universidade Federal do Rio de Janeiro (UFRJ). Some-se a isso o fato de que foi nessa mesma universidade que se iniciaram as pesquisas sobre línguas sinalizadas no Brasil, realizadas e lideradas por Ferreira-Brito (1984, 1990, 1995).

Essa efervescência linguístico-cultural certamente estimulou o nascimento do movimento político surdo brasileiro no Rio de Janeiro, o qual, de acordo com Berenz, teve como primeira manifestação pública de longo alcance a marcha "Surdos Venceremos”. Essa marcha ocorreu em setembro de 1994, em Copacabana, promovida por militantes da comunidade surda carioca, e teve como objetivo dar visibilidade à luta 
dos surdos pelo reconhecimento oficial da libras, pelo direito à educação em libras e pelo provimento de serviços de tradutores-intérpretes de libras/português.

O reconhecimento oficial da libras, no entanto, só se deu aproximadamente oito anos mais tarde, com a promulgação da Lei 10.436 de 24 de abril de 2002, a partir da qual a libras passa a ser considerada meio legal de comunicação e expressão das pessoas surdas brasileiras. Vale ressaltar, no entanto, que a referida lei não confere à libras o status de língua oficial, ou seja, de língua usada pelo governo para fins administrativos e legais (HOLMES, 2001).

O status linguístico da libras em relação à língua majoritária, o português, não é excepcional no cenário mundial. Segundo Reagan (2006), mesmo na Suécia, primeiro país a aprovar uma lei federal que reconhece uma língua de sinais, observa-se que essa língua não desfruta do mesmo prestígio que a língua majoritária. A referida lei simplesmente registra que a língua de sinais sueca é, de fato, uma língua, e por meio disso assegura alguns direitos a seus usuários. Com base em Reagan, pode-se dizer que a situação nos Estados Unidos parece ser pior, uma vez que a língua de sinais americana (ASL) não conta com reconhecimento oficial em todo o país, mas apenas em 35 dos seus 50 estados.

Apesar de reconhecer a língua da comunidade surda brasileira, a Lei de Libras também representa um mecanismo de legitimação do bilinguismo forçado vivido por ela. Conforme se pode ver no parágrafo único do Artigo $4^{\circ}$ da lei em questão, embora seja meio legal de comunicação e expressão dos surdos, a "Libras não poderá substituir a modalidade escrita da língua portuguesa". Sendo assim, pode-se dizer que, nos termos de Grosjean (1982), o bilinguismo experienciado pela comunidade surda brasileira é diglóssico, já que, nesse tipo de bilinguismo, uma das línguas (ou variedades da mesma língua) tem mais prestígio do que a outra.

Entretanto, o Decreto 5.626 de 22 de dezembro de 2005, que regulamenta a Lei de Libras, salvaguarda a condição dos surdos de usuários do português como segunda língua, ao determinar que a avaliação de suas produções em português escrito deve priorizar os aspectos semânticos, em detrimento dos aspectos relacionados à ortografia e à gramática, tal como esperados na avaliação de usuários de português como primeira língua. Além disso, o reconhecimento da diferença linguística dos surdos se manifesta no referido decreto, quando este também define esse grupo com base em sua 
experiência visual e expressão cultural através da libras, e não unicamente com base em sua condição audiológica.

Somando-se a isso, o Decreto 5.626 estabelece diretrizes para a educação de surdos, determinando que essa deve acontecer em escolas bilíngues, por meio de professores bilíngues na educação infantil e no ensino fundamental I. A partir do ensino fundamental II, o decreto orienta que ela se dê em escolas bilíngues ou escolas comuns. Caso ocorra em escolas comuns, fica determinada a obrigatoriedade da presença de tradutores-intérpretes de libras/português em todas as instituições federais de ensino, não só de educação básica. A inclusão de surdos em salas comuns de escolas regulares segue os princípios da "Política da Educação Especial na Perspectiva da Educação Inclusiva", segundo a qual todos os estudantes, independentemente de suas diferenças físicas, sociais, culturais, socioeconômicas ou linguísticas, devem aprender juntos (BRASIL, 2008).

No âmbito da educação inclusiva, as diferenças linguísticas dos alunos surdos são respeitadas não somente através do provimento de tradutores-intérpretes de libras/português, responsáveis pela sua acessibilidade linguística na sala de aula comum, mas também através de serviços de atendimento educacional especializado (AEE). Assim como para outros alunos com necessidades educacionais especiais, o AEE para surdos deve ser provido preferencialmente na mesma escola em que estudam, mas no contraturno, e por um professor com formação em educação especial. Cabe a esse profissional, além de trabalhar na sala de recursos multifuncionais com o ensino de libras e do português como segunda língua na modalidade escrita, orientar os professores das salas comuns sobre as singularidades linguístico-culturais de alunos surdos e suas implicações para os processos de ensino e avaliação desses alunos (BRASIL, 2008).

Além dessas orientações em serviço, conforme Resolução CNE/CEB n 2/2001, o professor da sala comum deverá ser capacitado durante sua formação inicial para lidar com as diferenças na sala de aula. A inclusão da disciplina "Libras" nos cursos de licenciatura, determinada pelo Decreto 5.626/2005, seguramente contribui com isso, uma vez que, segundo o referido decreto, por meio dessa disciplina devem-se formar professores "cientes da singularidade linguística dos alunos surdos" (BRASIL, 2005). Nesse sentido, embora tal disciplina não habilite os professores nem para a educação bilíngue, nem para o AEE voltado aos surdos (portanto, não tenha a pretensão de 
desenvolver fluência na libras), ela poderá, como se verá na seção seguinte, cumprir o importante papel de (in)formar e conscientizar os futuros professores acerca da opressão linguística sofrida pelas comunidades surdas por meio da negação de sua língua ao longo de sua escolarização, da concepção de surdez como diferença linguístico-cultural e não como deficiência, das diferenças culturais, das diferenças linguísticas dos alunos surdos e do papel do tradutor-intérprete de libras/português no espaço educacional. Cada um desses tópicos será discutido a seguir.

\section{Disciplina "Libras": formação para o respeito à diferença}

Segundo o Censo da Educação Superior de 2010, dentre os 17.769 cursos de licenciatura e fonoaudiologia credenciados, 13.617 (76,6\%) já incluíam a disciplina "Libras" em seus currículos (BRASIL, 2010). Apesar disso, de acordo com Costa e Lacerda (2015), poucos são os trabalhos que tratam da introdução dessa disciplina no ensino superior. Dentre os sete identificados pelos autores, apenas um investiga especificamente os conteúdos trabalhados nessa disciplina, por meio da análise das ementas de cinco universidades públicas do Estado do Rio de Janeiro (PERSE, 2011). Com base nos resultados de seu trabalho, Perse questiona se a disciplina "Libras" está atingindo o objetivo almejado pelo Decreto 5.626/2005, uma vez que as ementas analisadas revelam um foco no ensino de vocabulário.

Diante da falta de diretrizes para o estabelecimento dos conteúdos programáticos da disciplina "Libras", este trabalho propõe que ela atinja seu objetivo de conscientizar futuros professores das singularidades linguístico-culturais dos alunos surdos através da discussão de cinco temas inferíveis da própria legislação que assegura sua obrigatoriedade nos cursos de licenciatura. Como se verá nas subseções seguintes, esses temas se referem à opressão linguística sofrida pelas comunidades surdas por meio da negação de sua língua no processo educacional, à concepção de surdez como diferença e não como deficiência, às diferenças culturais, às diferenças linguísticas dos alunos surdos e, por fim, ao papel do tradutor-intérprete de libras/português no espaço educacional.

É fundamental destacar, no entanto, que não se quer dizer aqui que a aprendizagem da libras, ainda que em nível elementar, não deva integrar o conteúdo programático da disciplina em discussão. Pelo contrário! Aprender a se comunicar em libras, preferencialmente com professores surdos, conforme determinado pelo próprio 
Decreto 5.626/2005, tornará os temas aqui propostos ainda mais significativos para o futuro professor. Sendo assim, propõe-se unicamente que, além da introdução à comunicação em libras, os tópicos aqui elencados também componham as ementas dessa disciplina.

\subsection{A opressão linguística via educação}

Nos Incisos I e II do Artigo 22 do Decreto 5.626/2005, garante-se aos estudantes surdos o direito à educação bilíngue, a ser recebida em escolas e classes bilíngues onde a Libras e a Língua Portuguesa na modalidade escrita são utilizadas como línguas de instrução ao longo de todo o processo educativo. Embora na contemporaneidade essa garantia legal possa parecer natural para muitos, esse nem sempre foi o estado de coisas para os alunos surdos, nem no Brasil nem em outras partes do mundo. Familiarizar-se com o longo processo de opressão linguística que as pessoas surdas sofreram antes do advento de uma proposta de educação bilíngue para elas contribuirá não só para reforçar o valor dessa conquista da comunidade surda, mas também para conscientizar, sobretudo professores ouvintes, da dívida histórica que toda a sociedade tem com essa população.

Segundo Wilcox, Krausneker e Armstrong (2012), políticas linguísticas relativas às línguas sinalizadas têm sido geralmente estabelecidas por pessoas que, em muitos casos, não são surdas ou sinalizantes fluentes (2012, p.374). Isso explica por que mesmo as mais bem intencionadas abordagens educacionais para surdos podem ser consideradas, em maior ou menor grau, linguisticamente opressoras. Exemplos disso podem ser observados desde os primórdios da educação de surdos.

Charles-Michel de l'Epée (1712-1789), fundador da primeira escola pública para surdos, o Instituto Nacional para Surdos-Mudos de Paris, em 1779, foi o primeiro educador de surdos a reconhecer que estes têm uma língua, no seu caso, a língua de sinais francesa (LSF). Apesar disso, ele "considerava essa língua sem gramática e sem utilidade (na sua forma normalmente usada pelos surdos) para o ensino da língua escrita" (MOURA; LODI; HARRISON, 1997, p.332). Por essa razão, de acordo com Moura, Lodi e Harrison, ele desenvolveu um sistema artificial de sinalização, os chamados sinais metódicos, para representar gestualmente o francês e ser utilizado como meio de instrução para o ensino de leitura e escrita (foco da educação de surdos, na visão de l'Epée), em detrimento da oralização. 
Analisando abordagens educacionais voltadas para surdos em termos de políticas linguísticas, Wilcox, Krausneker e Armstrong (2012) consideram a abordagem de l'Epée uma manifestação do que Lane (1980) designa como dialetalização. Tipicamente, nesse tipo de política linguística, os usuários de uma língua ou dialeto são levados a pensar que sua forma de expressão linguística é inferior à língua dominante. No caso de l'Epée, isso ocorre quando este tratou as diferenças gramaticais da LSF em relação ao francês como evidências de sua inferioridade e insuficiência para desempenhar ela mesma o papel de língua de instrução.

O método de l'Epée, também conhecido como método francês ou manualismo, conviveu, segundo Capovilla (2000), até quase o fim do século XIX com o método alemão de Heinicke, que enfatizava a oralização. Porém, a partir de 1880, com o desastroso Congresso de Milão, instaurou-se o oralismo, fase da educação de surdos que primou pelo desenvolvimento da fala como forma de integrá-los à comunidade majoritária ouvinte. Esse método se opunha não apenas ao manualismo de l'Epée, mas também ao método empregado pelos primeiros educadores de surdos no século XVI. Como descrevem Wilcox, Krausneker e Armstrong (2012), enquanto estes últimos faziam uso língua de sinais e do alfabeto manual no ensino da fala (método combinado), os oralistas defendiam o método oral puro, pois acreditavam que a língua de sinais atrapalharia a aquisição da língua falada.

Depois do Congresso de Milão, a língua oral se tornou a língua de instrução e a língua de sinais passou a ser proibida na sala de aula. De acordo com Wilcox, Krausneker e Armstrong, em nome de seus ideais, assentados na falsa visão de supremacia da língua oral sobre a língua sinalizada, os oralistas tornaram corriqueiras práticas como fazer as crianças surdas sentarem sobre suas mãos para impedi-las de sinalizar (p. 378). Com base em Lane (1980), os referidos autores também descrevem o oralismo como uma forma de política linguística, desta vez, no entanto, do tipo substituição, dado que objetivava impor a língua majoritária sobre usuários de uma língua não-dominante, a língua de sinais, tentando eliminá-la.

Capovilla (2000) cita pesquisas realizadas na Inglaterra na década de 1970 que evidenciam o fracasso do oralismo. Segundo o autor, apesar de educados nessa perspectiva, apenas $25 \%$ dos surdos entre 15 e 16 anos apresentavam fala inteligível. Em relação ao seu nível de leitura e escrita, apenas $10 \%$ apresentavam um nível satisfatório, enquanto $30 \%$ continuavam analfabetos. Isso deu vazão a uma nova fase na 
educação de surdos, denominada comunicação total e caracterizada, de acordo com Wilcox, Krausneker e Armstrong, pelo ressurgimento dos sinais metódicos, que, apesar do novo nome, códigos manuais, tinham o mesmo objetivo que o sistema artificial de sinalização criados por l'Epée: representar manualmente a língua oral/escrita. Entre os sistemas criados nos Estados Unidos para o inglês, os autores citam o inglês sinalizado, o Signing Exact English e o Signing Essential English.

Conforme aponta Capovilla (2000), embora a comunicação total tenha tido o mérito, de certa forma, de reintroduzir a língua de sinais na sala de aula e, através dos códigos manuais, melhorar a comunicação entre surdos e ouvintes, os resultados ainda eram insatisfatórios. Os níveis de leitura e escrita de alunos surdos educados nessa perspectiva continuavam muito aquém de seus pares ouvintes. As razões deviam decorrer, dentre outras, do fato de que é impossível falar e sinalizar ao mesmo tempo, sem prejuízos ou à informação veiculada na fala, ou à informação representada manualmente. $\mathrm{O}$ autor menciona um estudo realizado em Copenhagen na década de 1970 que consistiu em colocar professores de surdos, que ministravam suas aulas falando e usando um código manual ao mesmo tempo, na pele de seus alunos. Precisamente, os pesquisadores apresentaram para esses professores filmagens de suas aulas sem o áudio e solicitaram que eles traduzissem o que estavam dizendo. Os resultados foram desconcertantes, já que os professores não foram capazes de entender sua própria sinalização.

$\mathrm{O}$ insucesso da comunicação total e o avanço das pesquisas linguísticas, demonstrando o estatuto de língua natural das línguas de sinais, iniciadas por William Stokoe, em 1960, nos Estados Unidos, culminaram com o início de uma nova fase na educação dos surdos: o bilinguismo. Nessa fase, finalmente, a língua de sinais passa a ser empregada como língua de instrução e a língua oral majoritária passa a ser ensinada na modalidade escrita. Capovilla (2000) faz menção a estudos realizados na Dinamarca na década de 1990 que apontam o sucesso do bilinguismo na educação de surdos. Segundo o autor, em um programa bilíngue realizado naquele país, observou-se mais do que uma melhora no nível de leitura dos alunos surdos. Observou-se também um progresso geral em termos de habilidades sociais, cognitivas e acadêmicas e até mesmo o desenvolvimento de uma visão mais positiva dos pais sobre a surdez de seus filhos.

Como visto, desde o Decreto 5.626/2005 a educação bilíngue passou a ser um direito dos alunos surdos no Brasil. Entretanto, por conta da Política Nacional de 
Educação Especial, à qual a educação de surdos esteve subordinada até 2014, esse direito esbarrou no movimento de inclusão educacional. Esse movimento objetivou pôr fim à educação especial (que abrangia as escolas de surdos) realizada de forma separada do sistema regular de ensino e incluir todos os alunos, independentemente de suas diferenças, na escola regular, mas oferecendo-lhes, no contraturno, um atendimento educacional especializado (AEE) (LODI, 2013). Porém, graças à luta da comunidade surda, através de um movimento que ficou conhecido como "Setembro Azul" e que foi instaurado como consequência das ameaças de fechamento das escolas de surdos iniciadas a partir da Conferência Nacional de Educação (CONAE) de 2010, conseguiuse garantir no Plano Nacional da Educação de 2014 o respeito ao direito à educação bilíngue, já garantido no decreto 5.626/2005, e o não fechamento das escolas de surdos.

Familiarizar futuros professores não só com as garantias legais que salvaguardam as diferenças linguístico-culturais dos alunos surdos, mas também com seus antecedentes históricos, certamente os conscientizará de seu importante papel na defesa dessas garantias, a fim de contribuir para que a longa história de opressão linguística não continue se repetindo em espaços educacionais.

\subsection{Concepções de surdez}

Embora o Artigo $2^{\circ}$ do Decreto 5.626/2005, ao definir a pessoa surda, destaque suas diferenças linguísticas e culturais, essa mesma definição inclui uma referência à perda auditiva. Dessa forma, o referido decreto põe lado a lado duas visões antagônicas sobre a surdez: a visão médico-terapêutica e a visão socioantropológica.

O déficit auditivo e as formas de, se não curá-lo, pelo menos compensá-lo, são foco das preocupações, sobretudo de profissionais da área da saúde. Certamente, por conta do valor desses profissionais na sociedade, sua visão acaba por alicerçar uma concepção patológica da surdez, a qual vem impactando a vida das pessoas surdas em todos os domínios há séculos. Reduzindo-se os surdos à sua condição audiológica, focaliza-se naquilo que eles "não têm" em relação à maioria das pessoas, à suposta norma, e, inevitavelmente, se lê a surdez como deficiência e desvantagem. No âmbito da educação, essa visão transforma a escola de surdos em uma clínica de reabilitação, o foco educacional em integração à sociedade ouvinte por meio do desenvolvimento da fala e os alunos em pacientes em tratamento. 
A concepção médico-terapêutica de surdez vem sendo duramente criticada pelas comunidades surdas e por pesquisadores que atuam nas áreas de educação de surdos e de linguística das línguas sinalizadas. O trabalho de Capovilla (2008) lança luz sobre algumas das razões que embasam essas críticas. Nesse trabalho, o autor deixa evidente que os surdos constituem um grupo extremamente heterogêneo, entre outros motivos, pelos diferentes graus de sua perda auditiva (leve, moderada, severa e profunda), ou ainda, em função do desenvolvimento da surdez antes, durante ou depois da aquisição da língua oral (surdez pré-linguística, peri-linguística ou pós-linguística). Esses argumentos, sozinhos, seriam suficientes para que não se tomasse a condição audiológica como traço definidor das pessoas surdas, uma vez que a surdez se manifesta de maneira variável nos indivíduos.

Conforme reportam Wilcox e Wilcox (2005), uma visão alternativa é oferecida por Ben Bahan, um renomado professor surdo de língua de sinais americana (ASL). Segundo os autores, Bahan propõe que as pessoas surdas sejam chamadas de 'pessoas visuais', pois assim elas passarão a ser vistas a partir daquilo que conseguem fazer e não do que não conseguem (2005, p. 17). Na mesma direção, pode-se citar um relato de um surdo norte-americano, Sam Supalla, atualmente professor universitário, documentado por Padden e Humphries (1988) em seu livro "Deaf in America: Voices from a culture". Nesse relato, Supalla, filho de uma família de pais e irmãos surdos, compartilha memórias de infância que envolvem uma garotinha com quem costumava brincar. Segundo ele, por muito tempo, essa garotinha lhe pareceu 'estranha', porque, além de ter muita dificuldade em entender sua sinalização, mesmo a mais simples, quando interagia com sua mãe, ela fazia uso de uma forma peculiar de comunicação que consistia em movimentos da boca. Ele conta que foi uma grande surpresa quando descobriu por sua mãe que a garotinha e sua família eram ouvintes que, diferentemente deles, surdos, além de se comunicarem por meio da fala, eram a maioria na população.

Tanto a proposta de Bahan quanto o relato de Supalla oferecem uma nova forma de olhar a surdez, uma vez que não apenas chamam a atenção para a diferença (e não deficiência) decorrente dela, mas também apontam para a relatividade do conceito de normalidade. Nos trabalhos de Skliar (2001), essa concepção é referida como visão socioantropológica da surdez, caracterizada, entre outras coisas, por reconhecer a atitude diferente da comunidade surda frente ao déficit auditivo, a língua de sinais como a língua natural dos surdos e, consequentemente, as pessoas surdas como membros de 
uma minoria linguística. Familiarizar-se com essa perspectiva, que se opõe frontalmente à visão médico-terapêutica, levará futuros professores a ver a escola de surdos ou a escola que inclui surdos simplesmente como escola, o foco educacional como sendo o desenvolvimento acadêmico e os alunos como pessoas em formação.

\subsection{Diferenças culturais}

Como visto na subseção anterior, ao definir as pessoas surdas, o Artigo $2^{\underline{0}}$ do Decreto 5.626/2005 menciona que essas manifestam "sua cultura principalmente pelo uso da Língua Brasileira de Sinais - Libras”. Essa definição, em consonância com a visão socioantropológica da surdez, permite considerara libras, em analogia ao tratamento dado por Wilcox e Wilcox (2005) à ASL, como uma língua estrangeira. Para os referidos autores, a ASL "é, em todos os sentidos da palavra, uma língua estrangeira", porque aprendê-la proporciona ao aprendiz a oportunidade de ver o mundo através de uma cultura diferente da dele (2005, p. 16). Em outras palavras, apesar de vernácula dos Estados Unidos, assim como acontece quando se aprende qualquer outra língua, os aprendizes de ASL são encorajados a ver o mundo através dos olhos da cultura surda. Graças a esse entendimento, desde a década de 1980, a ASL vem atendendo ao requisito de língua estrangeira em escolas e universidades nos Estados Unidos. Como visto, no Brasil, algo semelhante só começou a acontecer depois da promulgação do Decreto 5.626.

Para Wilcox e Wilcox, cultura é "a forma como uma pessoa faz sentido do mundo. São as ideias, conceitos, categorias, valores, crenças” (2005, p.95. Grifo do autor.). Dessa forma, para os autores, a cultura é algo imaterial, que se manifesta nas ações das pessoas. Como ilustração disso, eles analisam um fragmento de uma peça, intitulada "Meu Terceiro Olho", que foi representada pelo Teatro Nacional do Surdo em 1973 nos Estados Unidos. Nesse excerto, os atores surdos descrevem e representam ações que consideram típicas de pessoas ouvintes, objetivando satirizá-los por apresentarem, em sua visão, olhos pálidos e faces congeladas, além de bocas que se moviam sem parar e medo de tocar as outras pessoas.

À luz do trabalho do antropólogo Basso (1979) que analisou piadas apaches sobre o homem branco, Wilcox e Wilcox concluem que esse retrato do ouvinte revela os valores surdos, logo, elementos de sua cultura. Dado que pessoas ouvintes usam suas 
expressões faciais, movem suas bocas e tocam as outras pessoas de acordo com os padrões de sua cultura, a forma como os atores surdos interpretam essas ações em ouvintes sugere que os surdos realizam essas ações de maneira diferente, o que deve levá-los a atribuir a elas valores distintos daqueles atribuídos pelos ouvintes. O uso diferente da face e o consequente valor atribuído a ela estão provavelmente vinculados ao fato de as línguas de sinais expressarem informações gramaticais por meio desse canal. Já o uso distinto do toque e sua diferente valoração devem se vincular ao fato de este servir como uma das formas de vocativo.

Para conhecer mais a cultura surda, Wilcox e Wilcox sugerem a língua de sinais como uma porta e o "aprender a ver", título de seu livro, como a chave. Como aprender a ver, principalmente nesse caso, não consiste unicamente em apreciar as diferenças culturais, a disciplina "Libras", ao abordar esse e os outros temas aqui discutidos, pode ajudar os futuros professores, em primeiro lugar, a enxergar os surdos, historicamente invisibilizados e, em segundo lugar, a desenvolver uma nova visão sobre eles, baseada na sua diferença cultural e não na sua condição audiológica.

\subsection{Diferenças linguísticas}

O trabalho de William Stokoe nos Estados Unidos revolucionou a linguística ao demonstrar que a ASL e, por extensão, as línguas de sinais, são línguas naturais. No Brasil, estudos semelhantes só começaram na década de 1980 com as pesquisas da Prof $^{\text {a }}$. Lucinda Ferreira-Brito. Como já dito, o reconhecimento oficial da libras só se deu anos mais tarde, em 2002, através da Lei 10.436. Em seu Artigo 1ํㅡ, essa lei reconhece a libras como meio legal de comunicação e expressão de pessoas surdas do Brasil e a define como um "sistema linguístico de natureza visual-motora, com estrutura gramatical própria”. Apesar disso, o estatuto de língua natural da libras não faz parte ainda do senso comum e muitos mitos a seu respeito ainda povoam o imaginário não apenas popular, mas também de professores.

Diante de situação análoga nos Estados Unidos, Wilcox e Wilcox (2005) defendem que, em grande parte, o processo de aprendizagem de uma língua de sinais, pelo menos nos estágios iniciais, deve envolver não apenas a aprendizagem da língua propriamente, mas também a desaprendizagem de falsas ideias sobre ela. Entre essas ideias incorretas, pode-se citar a de que todos os surdos se comunicam através de uma mesma língua; ou outras, segundo as quais, as línguas de sinais foram inventadas pelos 
ouvintes;se resumem a gestos, mímicas e pantomimas; são totalmente icônicas; não têm a mesma capacidade expressiva que as línguas orais; e são baseadas nas línguas orais (WILCOX; WILCOX, 2005; JOHNSTON; SCHEMBRI, 2007).

Conforme argumentam Johnston e Schembri (2007), os surdos de todo o mundo não se comunicam através de uma mesma língua. Cada país tem uma ou mais línguas de sinais. A existência de uma língua de sinais internacional, o gestuno, usado, por exemplo, em congressos de que participam surdos de diferentes nacionalidades, reforça a falácia da universalidade. Além disso, segundo os referidos autores, as línguas de sinais se desenvolveram espontaneamente, assim como as línguas orais. Sendo assim, elas diferem de sistemas artificiais de sinalização criados para fins educacionais, em alguns casos, a partir das línguas de sinais. Uma evidência do estatuto de língua natural das línguas de sinais vem da língua de sinais nicaraguense, cujo nascimento pôde ser documentado. Segundo Johnston e Schembri, foi só na década de 1970, com a criação de escolas de surdos, que crianças surdas, até então espalhadas pela Nicarágua, tiveram a chance de conviver, formar uma comunidade e, para atender às suas necessidades comunicativas, desenvolver, paulatina e espontaneamente, a língua de sinais daquele país.

Johnston e Schembri esclarecem também que, embora gestos, mímicas e pantomimas sejam largamente empregados por surdos, mesmo em meio à sua sinalização, essas formas de comunicação não se confundem com a língua de sinais. Se não fosse assim, a sinalização de surdos seria compreensível a ouvintes que não sabem uma língua de sinais. Os autores ainda afirmam que essas línguas não são totalmente icônicas, já que há muitos sinais cuja forma não apresenta uma relação de motivação óbvia com o seu significado. Somando-se a isso, eles enfatizam que as línguas de sinais não são baseadas nas línguas orais, dado que, assim como mencionado na Lei de Libras, elas apresentam uma gramática própria, logo, constituem um sistema linguístico independente.

Cabe ressaltar que, além de possuírem uma gramática diferente não só em relação às línguas orais majoritárias com as quais convivem, mas também em relação a outras línguas sinalizadas, as línguas de sinais também se particularizam por se manifestarem em uma modalidade diferente das línguas faladas. Precisamente, enquanto estas últimas se manifestam sonoramente e são majoritariamente percebidas pela audição, as línguas de sinais se manifestam por meio de movimentos de partes externas 
do corpo e são percebidas pela visão. A diferença na modalidade está intimamente ligada a diferenças gramaticais. No entanto, do ponto de vista estrutural, há semelhanças inegáveis entre línguas sinalizadas e línguas faladas, fato que vem sendo usado para demonstrar o estatuto de língua natural de línguas como a libras, por exemplo.

De acordo com Xavier (2014), assim como nas línguas faladas, as palavras da libras, tradicionalmente chamadas de sinais, são decomponíveis em unidades menores. Isso equivale a dizer que essa língua e, por extensão, as línguas sinalizadas, operam não apenas no nível das unidades significativas (morfemas), mas também num nível sublexical, constituído por unidades distintivas (fonemas), capazes de distinguir palavras umas das outras. A principal diferença em relação às línguas orais reside na natureza dessas unidades. Enquanto em línguas como o português as unidades que constituem as palavras são sonoras e dos tipos consoantes e vogais, em línguas como a libras elas são gestuais-visuais e dos tipos: configuração de mão (estado dos dedos), orientação da palma, localização (lugar onde o sinal é feito), movimento da(s) mão(s) e expressões faciais e corporais. Apesar dessa diferença, Xavier documenta e analisa no nível sublexical um fenômeno universalmente atestado nas línguas naturais: a variação. Segundo ele, as unidades constitutivas dos sinais também podem variar em sua realização tanto por razões linguísticas (por exemplo, influência dos sinais adjacentes), quanto por razões extra-linguísticas (origem, idade, grau de formalidade, etc).

Como ilustração do primeiro tipo de variação, Xavier (2014) cita o sinal EU que, apesar de ser tipicamente produzido com o dedo indicador distendido e os demais fechados, pode ser realizado com diferentes configurações por influência da configuração de mão do sinal seguinte. Já como exemplo do segundo tipo de variação o autor cita o sinal ENTENDER que, em sua forma canônica, é produzido com a mão tocando a lateral da testa, mas, sobretudo em situações mais informais, é normalmente realizado com contato em posições mais baixas na lateral da face.

No nível da palavra, Xavier e Neves (2016) discutem dois processos recorrentemente observados nas línguas faladas também atestados na libras. Um deles, semelhante à derivação, consiste na criação de novos sinais e o outro, análogo à flexão, diz respeito à geração de formas diferentes de uma mesma palavra para fins de acréscimo de informações gramaticais. Concretamente, os autores citam como exemplo do primeiro tipo sinais compostos que, assim como em português, são formados por meio da junção de outras palavras/morfemas da língua (Ex.: ESCOLA, formado a partir 
dos sinais CASA e ESTUDAR). Já como exemplo do segundo, eles citam os chamados verbos direcionais, cuja forma se modifica em função da localização espacial associada ao seu sujeito ou objeto (Ex.: AJUDAR). Apesar dessas semelhanças com as línguas orais, são destacados no trabalho em questão tanto processos de formação de sinais quanto processos de geração de formas diferentes de um mesmo sinal que diferenciam a libras do português.

Entre os primeiros, Xavier e Neves (2016) listam casos em que a derivação de um sinal a partir de outro já existente não envolve o acréscimo de prefixos ou sufixos, mas a alteração do valor de uma ou mais unidades sublexicais. Um exemplo é o sinal PROBLEMA-DE-COMUNICAÇÃO que, conforme hipotetizam os autores, deriva do sinal COMUNICAÇÃO, realizado através de um movimento reto, contínuo e alternado das mãos no espaço em frente ao corpo. Diferentemente deste, no sinal derivado, PROBLEMA-DE-COMUNICAÇÃO, o movimento bidirecional, que sugere livre fluxo informacional entre pessoas que se comunicam, não se realiza plenamente, porque as mãos se chocam, sugerindo assim um bloqueio comunicacional. Os casos de geração de formas diferentes de uma mesma palavra, por sua vez, envolvem sinais como CIRURGIA, cuja localização é modificada para indicar a parte do corpo em que a ação expressa por ele se deu (Ex.: cirurgia nos olhos, cirurgia na face, etc). Ainda no nível da palavra, outras diferenças entre libras e português podem ser citadas, como, por exemplo, o fato de aquela não ter marcas de gênero e número em seus nomes e adjetivos ou marcas de tempo em seus verbos.

As diferenças entre libras e português também se manifestam em outros componentes de sua gramática. No nível da frase, por exemplo, Quadros (1999) documenta e analisa diferentes ordens de palavra a depender do tipo de verbo de que esta se constitui. Frases formadas a partir de verbos direcionais, como AJUDAR, admitem tanto a ordem sujeito-verbo-objeto, quanto a ordem sujeito-objeto-verbo. Porém, frases formadas por verbos não direcionais, como GOSTAR, são mais restritivas, uma vez que não admitem a ordem sujeito-objeto-verbo. Libras e português também podem diferir em relação a seus aspectos semânticos. Um exemplo claro disso envolve as conotações distintas que os conceitos "surdo" e "deficiente auditivo" têm para surdos e ouvintes. Enquanto para estes, o primeiro parece ser ofensivo e o segundo politicamente correto, para aqueles é o contrário. 
Conhecer algumas das semelhanças entre libras e português é de grande importância para o futuro professor, uma vez que elas reforçam o estatuto de língua natural da primeira. Por outro lado, conhecer algumas das diferenças entre essas mesmas línguas também é fundamental. Assim, o futuro professor se conscientizará de que o português escrito de alunos surdos se assemelha ao português de estrangeiros e que, para fins de avaliação, o conteúdo deve ser priorizado em detrimento de aspectos relacionados à gramática e ortografia.

\subsection{O tradutor-intérprete de libras/português}

De acordo com o Artigo 14 do Decreto 5.626, "as instituições federais de ensino devem garantir às pessoas surdas, obrigatoriamente, acesso à comunicação, à informação e à educação nos processos seletivos, nas atividades e nos conteúdos curriculares desenvolvidos em todos os níveis, etapas e modalidades de educação, desde a educação infantil até à superior”. Para isso, a Alínea b do Inciso III do $1^{\circ}$ Parágrafo do referido Artigo determina que as escolas devem prover tradutores-intérpretes de libras/português.

Além de investigar e denunciar os casos em que essa garantia legal não está sendo cumprida, cabe também questionar, como fez Quadros (2004) em uma pesquisa realizada entre 2001 e 2002 com tradutores-intérpretes de libras/português, considerados fluentes tanto em português quanto em libras, a qualidade da informação transmitida por eles em contexto de sala de aula inclusiva. O estudo de Quadros revelou que durante a interpretação para a libras dos conteúdos em português houve "(1) omissão de informações dadas na língua fonte; (2) acréscimos de informações inexistentes na língua fonte; (3) distorções semânticas e pragmáticas em menor ou maior grau do conteúdo veiculado na língua fonte; (4) escolhas lexicais inapropriadas" (2004, p.70).

Em um estudo subsequente, Quadros (2006) investiga a inclusão de surdos em escolas regulares do Estado de Santa Catarina. Um dos achados se refere ao fato de que, em sua grande maioria, os "professores-intérpretes" que atuam em salas regulares não têm qualificação profissional. Além disso, a autora denuncia que esses profissionais desempenham suas funções sozinhos e sem intervalos. Considerando-se o estudo de 2004, no qual Quadros observa que a informação transmitida pelos tradutoresintérpretes era completamente distorcida após a primeira hora de interpretação, vê-se que a situação em Santa Catarina é bastante preocupante, uma vez que aí se combinam 
falta de qualificação profissional e condições cognitivamente desfavoráveis para o desempenho da complexa atividade de tradução simultânea.

Conscientizar-se disso é de suma importância para o professor da escola inclusiva, dado que o desenvolvimento acadêmico do seu aluno surdo depende em grande medida da qualidade do trabalho dos tradutores-intérpretes de libras/português que, como se verá, poderá ser otimizado ou prejudicado pelas ações dos professores da sala comum. Nesse sentido, a disciplina "Libras" se constitui como espaço fundamental não somente para essa conscientização, mas também para o desenvolvimento de uma compreensão dos diferentes papeis que professores e tradutores-intérpretes de libras/português têm no processo de ensino e aprendizagem de alunos surdos.

Segundo Quadros (2004), discussões sobre o que compete ou não aos intérpretes educacionais nos Estados Unidos enfatizam, por exemplo, que não está entre suas atribuições "tutorar os alunos (em qualquer circunstância); apresentar informações a respeito do desenvolvimento dos alunos; acompanhar os alunos; disciplinar os alunos; realizar atividades gerais extraclasse" (2004, p.61). Sendo assim, o professor da sala comum precisa ter clareza quanto ao fato de que os alunos surdos são de sua responsabilidade tanto quanto os ouvintes e que, para efetivamente incluí-los, precisará trabalhar em parceria com os tradutores-intérpretes de libras/português.

Infelizmente, prática e teoria ainda se apresentam muito distantes. Em um trabalho que investigou a inclusão de um aluno surdo em uma escola privada de uma cidade do interior de São Paulo, Lacerda (2006), constatou, através de entrevistas com professores, tradutores-intérpretes de libras/português e alunos, a ausência de planejamento por parte dos professores de ações que levem em conta a presença dos tradutores-intérpretes ou mesmo do aluno surdo na sala de aula, resultando em atividades sem sentido para este. $\mathrm{O}$ estudo também evidenciou uma responsabilização dos tradutores-intérpretes pelo processo de ensino e aprendizagem do aluno surdo, o que, como vimos, representa uma total falta de compreensão do papel desses profissionais e um consequente desvio de sua função.

\section{Considerações finais}


Este artigo objetivou discutir de que forma a disciplina "Libras", obrigatória nos cursos de licenciatura, pode contribuir com a formação de professores com vistas à educação inclusiva. Para isso, primeiramente, traçou-se um breve panorama histórico desde os primórdios do movimento político surdo brasileiro até a promulgação da Lei 10.436 de 24 de abril de 2002 e do decreto 5.626 de 22 de dezembro de 2005, duas das mais importantes conquistas da comunidade surda nacional. Como visto, graças à primeira, a libras foi reconhecida como meio legal de comunicação e expressão das pessoas surdas brasileiras. Já graças à segunda, a referida lei foi regulamentada e a inclusão da libras como disciplina obrigatória nos cursos de licenciatura foi determinada.

Subsequentemente, foram discutidos cinco pontos, inferidos dessa legislação, cuja inclusão na disciplina em questão pode contribuir com a formação de professores para a educação básica inclusiva. Esses pontos compreendem questões históricas, filosóficas, linguístico-culturais, bem como questões referentes à atuação de profissionais. Precisamente, eles versam sobre a opressão linguística sofrida pelas comunidades surdas por meio da negação de sua língua no processo educacional, sobre a concepção de surdez como diferença e não como deficiência, sobre as diferenças culturais e linguísticas dos alunos surdos e, por fim, sobre o papel do tradutor-intérprete de libras/português no espaço educacional.

Cabe frisar, no entanto, que o que se propõe aqui não pretende substituir, mas complementar, os conteúdos que visam especificamente desenvolver habilidades comunicativas em libras, ainda que essas se restrinjam a um nível elementar por conta da pequena carga horária que a disciplina "Libras" normalmente apresenta nos currículos das licenciaturas. Seguramente, aprender a se comunicar na língua dos surdos, sobretudo com professores surdos, tornará todos os temas aqui elencados muito mais significativos para os futuros professores.

\begin{abstract}
The aim of this article is to discuss how the "Libras" subject, which is compulsory in undergraduate courses, can contribute even more to the training of teachers in the scope of inclusive basic education. In view of the lack of national guidelines for the constitution of a basic syllabus for the discipline "Libras", we suggest the inclusion of topics that can be inferred from the legislation that determines their compulsory nature
\end{abstract}


in these courses. These topics cover linguistic-cultural singularities of deaf students, historical and philosophical issues, as well as the performance of translators and interpreters of Libras and Portuguese.

Keywords: Libras. Teacher training. Inclusive education

\section{Resumen}

El objetivo de este artículo es discutir de qué manera la asignatura "Libras", obligatoria en las carreras de formación del profesorado, puede contribuir aún más con la formación de profesores en el ámbito de la educación básica inclusiva. Tomando en consideración la falta de normas nacionales para la construcción de una propuesta curricular básica para esa disciplina, se sugiere la inclusión de tópicos, inferibles de la legislación que determina su obligatoriedad en esas carreras y en sus contenidos. Estos temas cubren las singularidades lingüísticas y culturales de los estudiantes sordos, los problemas históricos y filosóficos, así como el desempeño de traductores e intérpretes de Libras y portugués.

Palabras clave: Libras. Grado. Educación inclusiva

\section{Referências}

BASSO, K. Portraits of "The Whiteman": Linguistic play and cultural symbols among the Western Apache. Cambridge: Cambridge University Press. 1979.

BERENZ, N. SurdosVenceremos: The rise of the Brazilian Deaf Community. In: MONAGHAN, L. et al. (Org.). Many Ways to Be Deaf: International Variation in Deaf Communities.Washington, DC: GallaudetUniversity Press, 2003. p. 173-193.

BRASIL. Ministério da Educação. Instituto Nacional de Estudos e Pesquisas Educacionais Anísio Teixeira - INEP. Censo da Educação Superior 2010. Brasília: 2010. Disponível em: <http://portal.inep.gov.br/web/guest/censo-da-educacao-superior>. Acesso em: 30 de abril de 2018.

BRASIL. Secretaria de Educação Especial. Política Nacional de Educação Especial na Perspectiva da Educação Inclusiva. Brasília, DF, jan. 2008a. [Documento elaborado pelo Grupo de Trabalho nomeado pela portaria n. 555/2007, prorrogada pela portaria $n$. 948/2007, entregue ao ministro da Educação em 7 de janeiro de 2008]. Disponível em: $<$ http://portal.mec.gov.br/index.php?option=com_docman\&view=download\&alias $=1669$ 0-politica-nacional-de-educacao-especial-na-perspectiva-da-educacao-inclusiva-

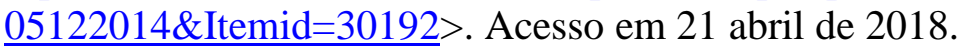

BRASIL. Decreto n. 5.626, de 22 de dezembro de 2005. Regulamenta a Lei n. 10436, de 24 de abril de 2002, que dispõe sobre a Língua Brasileira de Sinais - Libras, e o Artigo 18 da Lei 10098, de 19 de dezembro de 2000. Diário Oficial da República Federativa do Brasil, Poder Executivo, Brasília, DF, 23 de dez. de 2005. p. 28. Disponível em: 
$<$ http://www.planalto.gov.br/ccivil_03/_ato2004-2006/2005/decreto/d5626.htm>. Acesso $21 \mathrm{em}$ abril de 2018.

BRASIL. Lei 10.436, de 24 de abril de 2002. Dispõe sobre a Língua Brasileira de Sinais (LIBRAS) e dá outras providências. Diário Oficial da República Federativa do Brasil, Poder Executivo, Brasília, DF, 25 de abril de 2002. Disponível em:

$<$ http://www.planalto.gov.br/ccivil_03/leis/2002/110436.htm>. Acesso em 21 abrilde2018.

BRASIL. Ministério da Educação. Conselho Nacional de Educação. Resolução $\mathrm{CNB} / \mathrm{CEB} \mathrm{n}^{\circ} 2$, de 11 de setembro de 2001. Institui diretriz nacional para a educação especial na educação básica. Diário Oficial [da] República Federativa do Brasil, Poder Executivo, Brasília, DF, 14 set. 2001. Disponível em: http://portal.mec.gov.br/cne/arquivos/pdf/CEB0201.pdf>. Acesso em 21 abril de 2018.

CAPOVILLA, F. C. Filosofias educacionais em relação ao surdo: Do oralismo à comunicação total ao bilinguismo. Revista Brasileira de Educação Especial, v. 6, n. 1, p.99-116, 2000.

CAPOVILLA, F. C. O implante coclear em questão: benefícios e problemas, promessas e riscos. In: CAPOVILLA, F. C.; RAPHAEL, W. Dicionário enciclopédico ilustrado trilíngue: Língua de Sinais Brasileira. 3. ed. São Paulo: Edusp, 2008. p. 1519-1546.

COSTA, O. S.; LACERDA, C. B. F. de. A implementação da disciplina de Libras no contexto dos cursos de licenciatura. Revista Ibero-Americana de Estudos em Educação, v.10, n. esp. 759-772. 2015.

FERREIRA-BRITO, L. Similarities and Differences in Two Sign Languages.Sign Language Studies.Linstok Press, Silver Spring, USA, v. 42, p. 45-46. 1984.

FERREIRA-BRITO, L. Epistemic, Alethic, and Deontic Modalities in a Brazilian Sign Language. In: FISHER, S. D.; SIPLE, P. (Org.). Theoretical Issues in Sign Language Research. v. 1. Universityof Chicago Press. 1990. p. 229-260.

FERREIRA-BRITO, L. Por uma gramática de línguas de sinais. Tempo Brasileiro. UFRJ. Rio de Janeiro. 1995.

GROSJEAN, F.Life with Two Languages. Cambridge, MA: Harvard University Press, 1982.

HOLMES, J. An introduction to Sociolinguistics. 2a.edição, Harlow: Pearson Education, 2001.

JOHNSTON, T.; SCHEMBRI, A. Australian Sign Language (Auslan): An introduction to sign language linguistics. Cambridge: Cambridge University Press, 2007.

LACERDA, C. B. F. A inclusão escolar de alunos surdos: o que dizem alunos, professores e intérpretes sobre esta experiência. Cad.Cedes, Campinas, vol. 26, n. 69, p. 163-184, 2006. 
LANE, H. A chronology of the oppression of sign language in France and the United States.In: LANE, H.; GROSJEAN, F. (Org.). Recent perspectives on American Sign Language.Hillsdale, NJ: LawranceErlbaum, 1980. p. 119-161.

LODI. A. C. B. Educação bilíngue para surdos e inclusão segundo a Política Nacional de Educação Especial e o Decreto no 5.626/05. Educação \& Pesquisa, São Paulo, v. 39, n. 1, p. 49-63, jan./mar. 2013.

MOURA, M. C.; LODI, A. C. B.; HARRISON, K. M. R.. História e Educação: o Surdo, a Oralidade e o Uso de Sinais. In: LOPES FILHO, O. de C. (Org.). Tratado de Fonoaudiologia. São Paulo: Roca, 1997. p.327-357.

PADDEN, C.; HUMPHRIES, T..Deaf in America: Voices from a culture. Cambridge: Harvard University Press, 1988.

PERSE, E. L. Ementas de Libras nos espaços acadêmicos: que profissionais para qual inclusão? 2011. 202f. Dissertação (Mestrado em Linguística). Programa de Pós-

Graduação em Linguística, Universidade do Estado do Rio de Janeiro, Instituto de Letras, Rio de Janeiro, 2011.

QUADROS, R. M. PhrasestructureofBrazilian sign language. Tese de Doutorado. PUCRS. Porto Alegre. 1999.

QUADROS, R. M. $O$ tradutor e intérprete de língua de sinais brasileira. 2a . edição. Brasília, DF: MEC, 2004.

QUADROS, R. M. Políticas linguísticas e educação de surdos em Santa Catarina: espaço de negociações. Cad. CEDES, Campinas, v. 26, n. 69, p. 141-161. 2006.

REAGAN, T. Language Policy and Sign Languages. In: RICENTO, T. (Org.). An introduction to language policy: theory and method. Malden: Blackwell Publishing, 2006. p. 329-345.

SKLIAR, C. B. Educação \& Educação: Abordagens Sócio-Antropológicas em Educação Especial. In: SKLIAR. C. B. (Org.). Uma perspectiva sócio-histórica sobre a psicologia e a educação dos surdos. Porto Alegre: Mediação, 2001.

WILCOX, S. E.; KRAUSNEKER, V..; ARMSTRONG, D. F.. Language policy and the deaf community. In: SPOLSKY, B. (Org.). The cambridge handbook of language Policy. Cambridge: Cambridge University Press, 2012. p. 374-395.

WILCOX, S. E; WILCOX, P. Aprender a Ver. Rio de Janeiro: Arara Azul, 2005. Disponível em: 〈http://www.editora-arara-azul.com.br/pdf/livro2.pdf>.

XAVIER, A. N. Uma ou duas? Eis a questão! Um estudo do parâmetro número de mãos na produção de sinais da língua brasileira de sinais (libras). 2014. 146 f. Tese (Doutorado em Linguística) - Instituto de Estudos da Linguagem, Universidade Estadual de Campinas, Campinas, 2014. 
XAVIER, A. N.; NEVES, S. L. G. Descrição de aspectos morfológicos da libras. Revista Sinalizar, v.1, n.2, p. 130-151, 2016. Disponível em:

https://www.revistas.ufg.br/revsinal/article/view/43933/22087 Acesso em: 15 nov 2018. 